\title{
The Bologna Process: State of the Art after the 2007 London Ministerial Conference
}

\author{
Madalena Patricio \\ Universidad de Lisboa. Presidenta de AMEE
}

To introduce the theme nothing better than the a statement extracted from the 2007 EUA REPORT Trends V Universities shaping the European Higher Education: "Across Europe, there is no longer any question of whether or not Bologna reforms will be implemented, but rather a shift to considering the conditions in which implementation is taking place".

If it's true the Bologna Declaration is now a "non-stop process" involving 46 countries agreeing in 10 action lines it's also true that its implementation seems to be a rather "difficult process".

In what concerns Medical Education eight years after the Bologna Declaration was signed in 1999 by 29 countries and three before the established deadline for the desired "Harmonization of Higher Education" by 2010, the implementation of the Bachelor-Master (BA/MA) system remains the most controversial objective to be implemented. More problematic than the lack of consensus around this objective, is the fact that many stakeholders among medical education community seem not to be aware of the decision taken by his/her country. Moreover, this ambiguity is also extensive to some of the National Reports where the situation regarding Medicine is frequently absent or unclear.

To clarify the state of the art of the progress made so far regarding the BA/MA implementation in Medicine throug- hout Europe (and in those other countries which joined the Bologna Process), the results from a short survey developed in 2007 by AMEE (Association for Medical Education in Europe) and MEDINE (The Thematic Network on Medical Education in Europe) will be presented.

Implications for medical education will be analysed by confronting the survey results with the conclusions of the V Ministerial Meeting held in London in May 2007. If some objectives (like the 2-cycle system) are likely still to require reconsideration, it will be crucial to do this with a global perspective in order to overcome local and national problems. Independently of the position adopted by each country (adoption, rejection or discussion still going on) the Bologna Process cannot be reduced to this discussion.

The process is much more ambitious although in Medical Education too much energy seems to be focused on the discussion of the 2-cycle system. The Bologna Process constitutes a fantastic opportunity to develop and rethink Medical Education namely in terms of curriculum transparency, mobility, quality assurance, Higher European Education etc. It's not a good or bad thing in itself. The way each country will be implementing the process will determine "progression" or "regression" for Medical Education. For "progression" before acting locally, institutions must look globally through the implications of the existence of the European Higher Education Area after 2010. 